\section{Developing an Orientating Framework for Strategic Reflection: The Res-AGorA Responsibility Navigator}

\author{
by Ralf Lindner, Fraunhofer Institute for Sys- \\ tems and Innovation Research ISI, Germany, \\ Stefan Kuhlmann, and Bart Walhout, both \\ University of Twente, The Netherlands
}

The quest for Responsible Research and Innovation (RRI) has experienced a remarkable upsurge during the past few years. While the debate on RRI, as it is primarily labelled at the EU level, is far from being completed and stabilised, the demand for concrete conceptual approaches and instruments, which can contribute to the aim of making research and innovation more "responsible", has increased significantly (Lindner/Kuhlmann 2016, p. 22). To this end, an impressive number of research projects and coordination activities have been initiated during the recent past. In this broader context of projects funded by the EU, the Res-AGorA project ${ }^{1}$ had the objective to develop a comprehensive governance framework for RRI (EC 2011b, p. 7f.).

\section{Governing Towards Higher Levels of Responsibility: 10 Principles and Requirements of the Responsibility Navigator}

In the course of the project's three year life cycle, Res-AGorA co-constructed with practitioners and strategic decision-makers an orientating governance framework - the "Responsibility Navigator" (Kuhlmann et al. 2016). Based on an intensive empirical programme and a series of co-construction workshops, the Navigator was designed to support the identification and implementation of measures and procedures that can contribute to the transformation of research and innovation in such a way that responsibility becomes and institutionalised ambition (Kuhlmann et al. 2016, p. 135). After a brief overview of the project's main results, this contribution will describe Res-AGorA's specific approach to the development of the governance framework. ${ }^{2}$
Res-AGorA's "Responsibility Navigator" was conceived as a means to support decision-makers to govern research and innovation (R\&I) activities towards more conscious responsibility. In contrast to most other explicit, virtue-based frameworks for RRI, Res-AGorA's vantage point was that these cannot be the definite final manifestations for the different contexts at different levels across Europe. In fact, the definition of what is 'responsible' in R\&I is contested and will need constant re-negotiation and deliberation (Edler et al. 2015, p. 6).

Given the fluid and disputed understandings of responsibility in R\&I, the Res-AGorA consortium refrained from constructing a framework specifying the normative content of what responsible R\&I should be. Instead, the project team decided to develop a framework supporting the processes of governing towards higher levels of responsibility in R\&I, where the normative content is negotiated by the actors themselves as part of a continuous process of reflexive, anticipative and responsive adaptation of R\&I to changing societal challenges. The Responsibility Navigator intends to harness the self-governing capacities and capabilities of actors, and is conceived to provide orientation for actors to understand their responsibility challenges and to design, negotiate and implement their own context-specific understanding of responsibility (Lindner et al. 2016, p. 10f.)

Ten principles and requirements have been identified to allow for responsibility-related governance. The Responsibility Navigator ${ }^{3}$ defines each principle and illustrates them with fictive cases depicting possible situations and governance challenges and dilemmas.

The Responsibility Navigator is directed mainly at meso-level actors who perform leadership functions in R\&I organisations, set priorities, define policies and/or mediate between different levels and components of the innovation system.

\section{Research Design and Process}

In order to meet the requirements of the call and to arrive at a comprehensive governance framework for RRI, the consortium made a number of consequential considerations already during the early phase of proposal development. In principle, 
these key tenets framed the project's approach from early on and translated into the research design. Drawing on insights from a preliminary analysis of the RRI debate and the broader R\&I landscapes, the Res-AGorA partners concluded that the challenge for RRI governance is neither a shortage of possible normative directions nor the lack of governance arrangements and practices concerned with preventing harm.

\subsection{A Socio-normative Approach to Responsible Governance of R\&I}

First, RRI and related debates are inherently normative. Already the broader policy context within which any European governance framework for RRI would need to function is characterised by normative directions which are often competing and (partly) contradictory. This is reflected for instance in the European Union's goal to become a genuine innovation union in which "research and innovation are key drivers of competitiveness, jobs, sustainable growth and social progress" (EC 2011a, p. 4). In addition, the influential trend of orientating R\&I towards the so-called grand societal challenges or "new missions" can be observed (Daimer et al. 2012; Foray et al. 2012; van Oost et al. 2016). While most would welcome these high-level objectives, the concrete realisation of the normative claims will be contested in the context of our pluralistic societies. Res-AGorA acknowledged the need to identify conditions and credible mechanisms that facilitate the conditions for and capabilities of relevant actors to engage in constructive interactions.

Second, manifold governance arrangements and practices, which influence institutions and actors in the field of R\&I, already exist. Parts of these highly complex, heterogeneous and interwoven governance arrangements are concerned with preventing harm, assessing risks or protecting consumers. In addition, Technology Assessment, foresight processes, ELSA research and public engagement processes etc. are well-established approaches aiming to influence the directions and impacts of R\&I in acceptable and socially desirable ways. These numerous and multifaceted arrangements and mechanisms represent what Res-AGorA coined "RRI in the making" or the "de facto governance" (cf. Rip 2010) of responsible research and innovation (Randles et al. 2016a). The expectation was that the "success" of any new responsibility governance framework will depend on the way it relates to already existing governance practices, the more when these already explicitly deal with responsibility. Thus, any effective responsibility governance approach needs to take into account existing governance arrangements and should, where deemed useful, incorporate them constructively.

Consequently, the general thrust of the research design was to enable the project to learn from "RRI in the making", defined as an unfolding process co-evolving with different understandings of what it means to be responsible in a particular context. This was to be achieved by acknowledging that governance is constructed in practice(s). The focus on learning from this de facto responsibility governance can be characterised as "socio-normative" as the intention was to analyse tensions, barriers and opportunities in processes of RRI in the making in various situations, from large research programmes to sustainable production labels, together reflecting the richness of RRI goals and ambitions (Walhout et al. 2016, p. 47f.)

Res-AGorA did not aim to capture all perspectives of responsibility-related governance, but was interested in those practices in which actors work towards legitimate normative objectives and outcomes. These normativities become performed, qualified and institutionalized through various means and strategies and can stabilize into hard and soft regulatory instruments and institutions. Therefore, for the purpose of the project, governance was conceptualized as "the dynamic interrelation of involved (mostly organized) actors within and between organisations, their resources, interests and power, fora for debate and arenas for negotiation between actors, rules of the game, and policy instruments applied helping to achieve legitimate agreements." (Kuhlmann 2001; Benz 2006; Braun 2006)

Learning involves both understanding conditions and mechanisms, and evaluating the qualities and outcomes of governance processes. To this end, the research model was developed. 


\subsection{Research Model: Learning from $\mathrm{De}$ Facto Governance of Responsible Research and Innovation}

The project's guiding idea to learn from "RRI in the making" resulted in a particular strong empirical focus. The research design was developed to address two main research questions:

1. How is "RRI in the making" conditioned?

2. What are building components for the Res-AGorA governance framework?

Question 1 addresses the factors that shape governance processes in general, and how they condition the qualities and outcomes of these governance processes. Three interrelated and overlapping dimensions which condition "RRI in the making" can be distinguished:

- The governance arrangements and objectives around which actors mobilize resources and personnel in an attempt to realize responsibility in R\&I,

- the actor landscape involved,

- the de facto governance practices, i.e. the places and spaces in which the RRI governance arrangements are called upon, objectives are negotiated and instruments are implemented.

Differentiating between these three dimensions supported the exploration of a set of case studies of "RRI in the making", where the "RRI governance arrangement" was the unit of analysis. By this we refer to responsible research and innovation policies as these are characterised by structural aspects - such as modes of regulation (e.g. hard/soft) - type of responsibility (e.g. prospective/retrospective), type of ethical principles, or the relative position within the broader landscape of R\&I and responsibility governance arrangements. Such structural aspects condition the related process of "RRI in the making". These can be the "fora for debate and arenas for negotiation" in our conceptualisation of governance, but also procedures or particular problem framings. Processes of agenda setting, the articulation of ambitions and translations into instruments are examples of processes through which strategic behaviour occurs and certain frames gain dominance, while other perspectives can be silenced (Walhout et al. 2016, p. 50f.).
Question 2 is about drawing lessons from the empirical research programme for the design of an overarching governance framework for RRI. The case study analysis was organised to identify building components for this framework. These were related to the conditions traced under research question 1 . The building components were linked to the demonstrated "success" or "failure" in the case studies. For example, what could improve the "games" by which actors work towards aligning different claims of effectiveness and legitimacy?

The challenge for Res-AGorA was to capture in which aspects and to which extent the de facto governance of responsible research and innovation is "doing well". Following our conceptualization of governance, we argue that governance processes are "successful" if there is an acceptance of a shared understanding of responsibility, and the development and application of instruments, mechanisms and processes which serve to embed this shared understanding into practice to an extent that it guides and structures reflections, learning, behaviour or decision making. This was conceptualised by an evaluative frame consisting of four dimensions:

The first two qualifications of the frame reflect the project's understanding of the challenge for actors in responsibility-related governance to operate with legitimate and effective arrangements, while at the same time these claims about legitimacy and effectiveness are an abundant source of contestation in the governance of responsibility. Consequently, "governance success" can be assessed in terms of how well this dual dynamic is coped with. The range of factors identified as essential for coping with these challenges were grouped under the headings of "responsibilisation" and "contestation" (Walhout et al. 2016, p. 50-52):

- "Responsibilisation" is about the governance of (self-) stimulating actors to care for their duties of being anticipatory, reflexive, responsive, etc. by drawing on a clear understanding of their responsibilities and un-coerced application of values. This stimulating governance can take the form of facilitating, equipping and rewarding of actors to take their responsibilities seriously. ${ }^{4}$ 
- Managing contestation is about the governance of deliberating and negotiating competing claims of responsibility, effectiveness and legitimacy, which are the result of different understandings, framings and evaluations of the need for and processes and instruments by which normative objectives are to be accomplished (whether or not specifically articulated as RRI).

With regard to the dual challenge of responsibilisation and contestation, the interactions between the "actors and factors" were qualified in terms of "constructive" and/or "productive":

- Constructive interactions can be characterised by an adequate treatment of the issue(s) under discussion (including the framing of the problem) and mobilisation of resources (from mental to financial). Here, "adequate" is not simply an objective measure, but set in context of the nature and distance between actor perceptions of what the RRI "problem" is, and how to resolve it in governance terms (e.g. the mobilisation of, or reference to, particular governance instruments, and their effective utilisation).

- Productive interactions bring about transformation, either in the behaviour or attitude of actors, in line with new understandings of responsibility, working towards a higher level of shared understanding of responsibility or in responsive/reflexive improvement in the governance arrangement itself (which then defines and supports specific goals).

Conceptually these four qualifications translated into a matrix. For the purpose of providing an analytical grid for the case study investigations, the matrix was supplemented with a number of descriptors depicted in Table 1.

\subsection{Identifying Building Components for a Framework Prototype and Co- construction}

A hallmark of Res-AGorA was its extensive empirical programme, motivated by the objective to learn from "RRI in the making" in order to derive lessons for the development of a governance framework for responsible research and innovation. 26 case studies were conducted in three stages. The selection aimed at reflecting a broad variety of governance situations in R\&I, encompassing different entry points and foci, reaching from the role of specific governance instruments and processes, cases on organisational and institutional change, to whole multi-actor innovation system responses. ${ }^{5}$ The case studies were guided by the research model outlined in section 2.2.

The cross-analysis was undertaken by comparing and contrasting the cases with the aim to identify similarities, differences and common patterns. The result of this analytical process was the identification of 13 transversal lessons on the governance and institutionalisation of responsibility in R\&I (Randles et al. 2015).

The 13 lessons represent the conceptual backbone of the Res-AGorA governance framework prototype. Complementary inputs were generated by other essential empirical and conceptual strands of the project, namely the analyses of the foundations of and evolving discourse about RRI (Arnaldi et al. 2016; Randles et al. 2016b; Tancoigne et al. 2016), the insights derived from the monitoring of RRI trends in 16 European countries $^{6}$, and theory-inspired conceptual reflections (more extensively covered in Kuhlmann et al. 2015). The resulting prototype comprised of ten principles, grouped in three dimensions.

Table 1: Evaluative frame

\begin{tabular}{lll}
\hline & Constructive (input requirements) & Productive (transformation) \\
\hline Responsibilisation & - Actor inclusion & $\bullet$ Actors change behaviour/attitude in line with new \\
& - Robustness of the knowledge base & understandings of responsibility \\
& - Capacities for learning & \\
& - Embedding of responsibility & \\
Contestation & - Procedures and 'rules of the game' & $\bullet$ Governance arrangements align with or are changed \\
& - Transparency & towards input requirements (constructive) \\
\hline
\end{tabular}

Source: Walhout et al. 2016, p. 52 
With the completion of the prototype, the project entered its so-called co-construction phase. This was a deliberative and interactive process involving more than 80 high-level stakeholders from science, industry, civil society and policy-making with the aim of testing, further developing and refining the building components for a governance framework for responsible research and innovation. ${ }^{7}$ The series of five different thematic and stakeholder group specific workshops generated substantial feedback on how to further develop the governance framework, and numerous proposals on how to increase its usability and added-value for the envisioned target users. The end result of this process was the Responsibility Navigator.

Numerous project elements were intentionally designed to contribute to a high degree of utility for the potential users, user-friendliness, and eventually 'robustness' of the governance framework by incorporating the views and the constructive feedback from a broad range of stakeholder groups and critical sounding boards. However, the project life-cycle ended before the Navigator could be applied in settings beyond Res-AGorA. Against this background we are excited to observe that three new EU-funded projects are explicitly applying the Responsibility Navigator in order to support responsibility-related institutional transformations, and that a number of project proposals are claiming to do so if funding is granted.

\section{Notes}

1) Responsible Research and Innovation in a Distributed Anticipatory Governance Frame. A Constructive Socio-normative Approach. Res-AGorA was funded by the European Union's Seventh Framework Programme for research, technological development and demonstration under grant agreement no 321427. For more information: http://www.res-agora.eu

2) To a large extent, the following directly draws on different project reports and publications, particularly Kuhlmann et al. (2015, 2016), Lindner et al. (2016), Walhout et al. (2016).

3) The complete Responsibility Navigator is available at http://www.responsibility-navigator.eu.

4) Applying the concept of "responsibilisation" was inspired by Dorbeck-Jung/Shelley-Egan (2013).
5) The Res-AGorA case studies are available at http://res-agora.eu/case-studies/

6) The findings of RRI Trends are available at https:// rritrends.res-agora.eu/; Mejlgaard/Griessler (2016) provide a preliminary analysis of the monitoring data.

7) The co-construction workshop method, which was developed by the Res-AGorA project and can be used to support the application of the Responsibility Navigator, is available at: http://responsibility-navigator.eu/co-construction-method/

\section{References}

Arnaldi, S.; Gorgoni, G.; Pariotti, E., 2016: RRI as a Governance Paradigm: What is New? In: Lindner, R.; Kuhlmann, S.; Randles, S. et al. (eds.): Navigating Towards Shared Responsibility in Research and Innovation. Approach, Process and Results of the Res-AGorA Project. Karlsruhe, pp. 23-29; https:// indd.adobe.com/view/eaeb695e-a212-4a34-aebab3d8a7a58acc (download 28.7.16)

Benz, A., 2006: Governance in Connected Arenas Political Science Analysis of Coordination and Control in Complex Control Systems. In: Jansen, D. (ed.): New Forms of Governance in Research Organizations. From Disciplinary Theories towards Interfaces and Integration. Heidelberg, pp. 3-22

Braun, D., 2006: Delegation in the distributive policy arena: the case of research policy. In: Braun, D.; Gilardi, F. (eds.): Delegation in Contemporary Democracies. London, pp. 146-170

Daimer, S.; Hufnagl, M.; Warnke, P., 2012: Challenge-oriented Policy-making and Innovation Systems Theory. Reconsidering Systemic Instruments. In: Fraunhofer ISI (ed.): Innovation System Revisited. Experiences from 40 Years of Fraunhofer ISI Research. Stuttgart, pp. 217-234

Dorbeck-Jung, B.; Shelley-Egan, C., 2013: Meta-Regulation and Nanotechnologies: The Challenge of Responsibilisation Within the European Commission's Code of Conduct for Responsible Nanosciences and Nanotechnologies Research. In: NanoEthics 7/1 (2013), pp. 55-68

EC - European Commission, 2011a: Horizon 2020 The Framework Programme for Research and Innovation, Brussels

EC-European Commission, 2011b: Work Programme 2012. Capacities Part 5: Science in Society. European Commission C(2011)5023 of 19 July 2011, Brussels

Edler, J.; Randles, S.; Gough, C., 2015: Final Synthesis and Lessons Report. Res-AGorA empirical programme of case studies, transversal lessons and illus- 
trations to the Responsibility Navigator. Deliverable of the Res-AGorA project D3.7. Karlsruhe; http:// res-agora.eu/assets/Res-AgorA_321427_Del_3-7_final.pdf (download 28.7.16)

Foray, D.; Mowery, D.C.; Nelson, R.R., 2012: Public R\&D and Social Challenges: What Lessons from Mission R\&D Programms? In: Research Policy 41 (2002), pp. 1697-1702

Kuhlmann, S., 2001: Governance of Innovation Policy in Europe - Three Scenarios. In: Klein, H.; Kuhlmann, S.; Shapira, P. (eds.): Research Policy. Special Issue Innovation Policy in Europe and the US: New Policies in New Institutions 30/6 (2001), pp. 953-976 Kuhlmann, S.; Ordonez-Matamoros, G.; Walhout, B. et al., 2015: Interim Design Requirement Report. Deliverable D4.8 of the Res-AGorA project. Karlsruhe; http://res-agora.eu/assets/Res-AGorA_Del_4-8-Final.pdf (download 28.7.16)

Kuhlmann, S.; Edler, J.; Ordóñez-Matamoros, G. et al., 2016: Responsibility Navigator. In: Lindner, R.; Kuhlmann, S.; Randles, S. et al. (eds.): Navigating Towards Shared Responsibility in Research and Innovation. Approach, Process and Results of the Res-AGorA Project. Karlsruhe, pp. 135-158; https:// indd.adobe.com/view/eaeb695e-a212-4a34-aebab3d8a7a58acc (download 28.7.16)

Mejlgaard, N.; Grissler, E., 2016: Monitoring RRI in Europe: Approach and Key Observations. In: Lindner, R.; Kuhlmann, S.; Randles, S. et al. (eds.): Navigating Towards Shared Responsibility in Research and Innovation. Approach, Process and Results of the Res-AGorA Project. Karlsruhe, pp. 115-118; https:// indd.adobe.com/view/eaeb695e-a212-4a34-aebab3d8a7a58acc (download 28.7.16)

Lindner, R.; Kuhlmann, S., 2016: Responsible Research and Innovation und die Governance von Forschung \& Innovation: Herausforderungen und Prinzipien. In: Forschung: Politik - Strategie - Management 1/9 (2016), pp. 22-27

Lindner, R.; Kuhlmann, S.; Bedsted, B. et al., 2016: Introduction: The Res-AGorA journey. In: Lindner, R.; Kuhlmann, S.; Randles, S. et al. (eds.): Navigating Towards Shared Responsibility in Research and Innovation. Approach, Process and Results of the Res-AGorA Project. Karlsruhe, pp. 9-19; https://indd.adobe. com/view/eaeb695e-a212-4a34-aeba-b3d8a7a58acc (download 28.7.16)

Randles, S.; Edler, J.; Gee, S., 2015: Governance and the Institutionalisation of Responsible Research and Innovation in Europe. Transversal Lessons from an Extensive Programme of Case Studies. Stakeholder Report. Deliverable of the Res-AGorA project
D3.6. Karlsruhe; http://res-agora.eu/assets/Res-AgorA_321427_Del_3-6_final.pdf(download 28.7.16)

Randles, S.; Edler, J.; Gee, S. et al., 2016a: Res-AGorA Case Studies: Drawing Transversal Lessons. In: Lindner, R.; Kuhlmann, S.; Randles, S. et al. (eds.): Navigating Towards Shared Responsibility in Research and Innovation. Approach, Process and Results of the Res-AGorA Project. Karlsruhe, pp. 65-72; https://indd.adobe.com/view/eaeb695e-a212-4a34aeba-b3d8a7a58acc (download 28.7.16)

Randles, S.; Laredo, P.; Loconto, A. et al., 2016b: Framing and Frameworks: Six Grand Narratives of De Facto RRI. In: Lindner, R.; Kuhlmann, S.; Randles, S. et al. (eds.): Navigating Towards Shared Responsibility in Research and Innovation. Approach, Process and Results of the Res-AGorA Project. Karlsruhe, pp. 31-36; https://indd.adobe.com/view/eaeb695e-a2124a34-aeba-b3d8a7a58acc (download 28.7.16)

Rip, A., 2010: De Facto Governance of Nanotechnologies. In: Goodwin, M.; Koops, B.-J.; Leenes, R. (eds.): Dimensions of Technology Regulation. Nijmegen, pp. 285-308

Tancoigne, E.; Randles, S.; Joly, P.-B., 2016: Evolution of a Concept: A Scientometric Analysis of RRI. In: Lindner, R.; Kuhlmann, S.; Randles, S. et al. (eds.): Navigating Towards Shared Responsibility in Research and Innovation. Approach, Process and Results of the Res-AGorA Project. Karlsruhe, pp. 39-44; https://indd.adobe.com/view/eaeb695e-a212-4a34aeba-b3d8a7a58acc (download 28.7.16)

van Oost, E.; Kuhlmann, S.; Ordóñez-Matamoros, G.H. et al., 2016: Futures of Science with and for Society: Towards Transformative Policy Orientations. In: Foresight - The journal of future studies, strategic thinking and policy 18/3 (2016), pp. 276-296; http://dx.doi. org/10.1108/FS-10-2014-0063 (download 28.7.16)

Walhout, B.; Kuhlmann, S.; Ordonez-Matamoros, G. et al., 2016: Res-AGorA Concepts and Approach. In: Lindner, R.; Kuhlmann, S.; Randles, S. et al. (eds.): Navigating Towards Shared Responsibility in Research and Innovation. Approach, Process and Results of the Res-AGorA Project. Karlsruhe, pp. 47-53; https://indd.adobe.com/view/eaeb695e-a212-4a34aeba-b3d8a7a58acc (download 28.7.16)

\section{Contact}

Dr. Ralf Lindner

Fraunhofer Institute for Systems and Innovation

Research ISI

Breslauer Straße 48, 76139 Karlsruhe

Phone: +49 721 6809-292

Email: ralf.lindner@isi.fraunhofer.de 